\title{
Meningeal Solitary Fibrous Tumor/Hemangiopericytoma, Grade 3
}

National Cancer Institute

\section{Source}

National Cancer Institute. Meningeal Solitary Fibrous Tumor/Hemangiopericytoma,

Grade 3. NCI Thesaurus. Code C92652.

A solitary fibrous tumor/hemang iopericytoma that arises from the meninges. It most

often corresponds to the tumor previously diagnosed as anaplastic

hemangiopericytoma. 